\title{
"Na luta pela vida, uteis a si e á Pátria": perfil biográfico-profissional do Professor Benjamin Flores ${ }^{1}$
}

"In the struggle for life, useful to themselves and to the nation": a biographic and professional profile of Teacher Benjamin Flores

"En la lucha por la vida, útiles para si mismas y para la patria": perfil biográfico-profesional del maestro Benjamin Flores

\author{
Betânia de Oliveira Laterza Ribeiro \\ Universidade Federal de Uberlândia (Brasil) \\ https://orcid.org/0000-0002-3708-4506 \\ http://lattes.cnpq.br/6186135872782431 \\ laterzaribeiro@uol.com.br \\ Elizabeth Farias da Silva \\ Universidade Federal de Santa Catarina (Brasil) \\ https://orcid.org/0000-0002-0407-5566 \\ http://lattes.cnpq.br/8900149791941066 \\ lizet@uol.com.br
}

\section{Resumo}

Benjamin Flores (1872-1950) se empenhou em promover condições de existência e trabalho à sociedade de Belo Horizonte na primeira metade do século XX. Suas iniciativas incluem uma escola profissional para mulheres, quando a urbe se abria a uma atuação e produção social feminina maior na esfera pública. Tal ação pode ser vista como à frente de seu tempo, maturada num processo de autoconscientização de sua realidade social. Esse artigo incide na atuação profissional de Flores para reconhecer, em sua conduta, antecedentes de seu projeto educacional, com base em cartas, jornais e escrituração escolar, entrevistas e fotografias, fontes lidas com um olhar de intenção histórico-dialética para ver continuidades e permanências, convergências e contradições, coerência e fragmentação. Os resultados apontam como homem de sensibilidade quanto às demandas sociais que buscou atuar em instâncias variadas como agente público e, sobretudo, como professor que entendeu o ensino em suas várias facetas.

Palavras-chave: Belo Horizonte, escola profissional para mulheres, esfera pública.

\footnotetext{
${ }^{1}$ A pesquisa subjacente a este artigo foi financiada pela Fundação de Amparo à Pesquisa do Estado de Minas Gerais (Fapemig) e pelo Conselho Nacional de Desenvolvimento Científico e Tecnológico (CNPq).
} 


\begin{abstract}
Benjamin Flores (1872-1950) searched to promote conditions of existence and work for Belo Horizonte city society in the first half of the twentieth century. His actions included a professional school for women when this city opened up to a greater feminine social performance and production in the public sphere. His action may be seen as ahead his time and matted in a process of self-awareness of his social reality. This article focuses on his professional performance to recognize in his actions antecedents of his educational project. It is based on letters, newspapers, school bookkeeping, interviews and photographs, read with a historical-dialectic gaze looking for continuities and permanence, convergences and contradictions, coherence and fragmentation. Results reveal a man of sensibility regarding the social demands that sought to act in various instances as a public agent and, above all, as a teacher who understood teaching in his various facets.
\end{abstract}

Keywords: Belo Horizonte, school for women professional training, public sphere

\title{
Resumen
}

Benjamin Flores (1872-1950) buscó promover condiciones de existencia y trabajo para la sociedad de Belo Horizonte en la primera mitad del siglo XX. Sus acciones incluyeron una escuela profesional para mujeres cuando esta ciudad se abrió a un mayor rendimiento y la producción social de las mujeres en la esfera pública. Su acción fue avanzada en su tiempo y derivada de un proceso de autoconciencia de su realidad social. Este artículo se centra en su trabajo para reconocer en sus acciones antecedentes de su proyecto educativo, basado en cartas, periódicos, documentación escolar, entrevistas y fotografías, analizados con una mirada histórica dialéctica en busca de continuidades y permanencia, convergencias y contradicciones, coherencia y fragmentación. Los resultados revelan a un hombre de sensibilidad con respecto a las demandas sociales que buscó actuar en varios casos como agente público y, sobre todo, como maestro que entendía la enseñanza en sus diversas facetas.

Palabras-clave: Belo Horizonte, escuela de formación profesional para mujeres, esfera pública. 


\begin{abstract}
Nunca o viamos parado. Na rua, sempre apressado, cheio de embrulhos. Não podia parar, para não perder o horario de suas obrigações. [...] uma figura original de lutador, de um genero que não existe mais.
\end{abstract}

JOSÉ CLEMENTE, 1950

\title{
Introdução
}

O mandato do presidente da República Nilo Peçanha (1867-1924) durou quinze meses e um dia. Mas, entre 15 de junho de 1909 e 15 novembro de 1910, o ideal de desenvolvimento e progresso que marcou a consolidação da República foi reforçado com a criação do Ministério da Agricultura, Indústria e Comércio. A inclusão da indústria e do comércio nas ocupações desse órgão não só deu uma medida dos rumos que a economia tomaria, mas também se abre à compreensão de que, como diretriz central em uma nação, a orientação econômica teria impactos na vida social. O projeto de industrialização e comercialização do produto fabril, por exemplo, teria como lócus a área urbana, de baixa densidade populacional (os distritos industriais) e alta densidade demográfica (região central da cidade e de bairros). Também criava expectativa de emprego nessas áreas geográficas e econômicas, ou seja, supunha criar demanda por mão de obra que tivesse um mínimo de qualificação.

A intenção de regulamentar as atividades produtivas com a criação do referido Ministério pressupôs, ainda, pensar na formação de mão de obra para fazer a produção acontecer, seja pela manufatura ou comercialização. Lidar com a produção industrial, com as relações de compra de venda e a administração industrial e comercial exigia pessoal com preparo específico, em especial na indústria, lócus de área como mecânica, eletricidade, hidráulica e metalurgia, por exemplo. Por outro lado, habilidades relativas à capacidade de escrita (datilografia, domínio de formas documentais como contrato, ata, memorando, pedido, nota fiscal etc.) e escrita contábil (conhecimento de livros e formas de registro e demais documentos da contabilidade etc.) se projetavam como objeto das políticas educacionais. Como ação complementar e coerente com a criação do Ministério, Nilo Peçanha decretou a criação o ensino profissional primário gratuito nas capitais, por meio do decreto 7.566/1909. Esse documento prescreveu a criação de escolas de aprendizes artífices.

De fato, o ensino profissional ganhou corpo em instâncias não só governamentais, mas também da sociedade civil. Uma medida de sua projeção em meio a não políticos pode ser a realização de congressos. Nesses eventos, educadores e intelectuais interessados no ensino expuseram teses como aquelas que estruturaram a segunda edição do Congresso Brasileiro de Instrução Primária e Secundária, em Belo Horizonte/MG (28 set.- 4 out. 1912) $)^{2}$. Em meio à reiteração de atributos do ensino primário (liberdade e gratuidade, por exemplo), condições, meios e instrumentos (bibliotecas e museus), destacaram-se teses sobre o ensino profissional. No dizer de Rocha (2012, p. 231), os congressistas expressaram uma compreensão de ensino profissional "em geral" não como algo "estritamente vinculado às massas", e sim como ensino que "[...] deve se especializar, mantendo inclusive elos com o ensino secundário".

O ensino profissional de mulheres não ficou alheio aos interesses dos congressistas, traduzidos em questionamentos: "Para a perfeita educação feminina [...] nos differentes aspetos moral, intellectual, physico, profissional e social: quaes os meios de que se deve lançar mão actualmente? [...] não convém preconizar a fundação das Escolas Maternaes, das Escolas de Profissões Domesticas, dos Institutos Profissionaes Femininos?" (CONGRESSO

\footnotetext{
2 O primeiro congresso aconteceu em São Paulo, em 1911; o terceiro, na Bahia, em 1913; o quarto, na cidade do Rio de Janeiro, em 1922.
} 
BRASILEIRO DE INSTRUÇÃO PRIMÁRIA, 1912, p. 8, 27). A julgar pelas indagações, a profissionalização de mulheres teria como objeto e objetivo não só formá-las para o exercício de profissões que se abriam à mão de obra feminina, mas também cuidar da moral e integridade física e social. Era a essência da "perfeita educação" delas. Supostamente, eram destituídas não só de habilidades intelectuais e manuais; também de valores morais, senso de cuidado físico e despreparo para a realidade social da esfera pública do trabalho não domiciliar.

Aqueles questionamentos foram, então, o ponto de partida para debates na quinta comissão do congresso de Belo Horizonte, cujos membros incluíram professores - sendo um deles Benjamin Flores - padres, cônego e outros com título de doutor. Voz menos conhecida em meio a nomes como Delfim Moreira e Estevam de Magalhães, Flores se destacou pela ação. No ano seguinte ao congresso, fez do discurso sobre ensino profissional uma prática ao fundar uma escola voltada ao comércio, em 1912, e uma voltada à profissionalização de mulheres.

A escola para mulheres foi objeto de estudo mais amplo ${ }^{3}$ que, de fato, trata do fundador, mas de forma difusa. Assim, esse artigo visa complementá-lo ao agrupar dados que permitem compor um perfil biográfico-profissional de Benjamin Flores: origens sóciofamiliares, formação escolar e familiar e atuação profissional. A composição desse perfil se embasa, sobretudo, no que foi publicado na imprensa de Minas Gerais e outros estados; em entrevista - durante a pesquisa subjacente a este estudo - com Teresa Flores Moura, neta de Benjamin Flores, e em seu acervo. Registros documentais da família forneceram dados importantes: manuscritos, fotografias, recortes de jornal, impressos escolares e outros. Também a entrevista com uma ex-aluna de Benjamin Flores na Escola Profissional Feminina ajudou a compor o perfil.

\section{Origens familiares e educacionais}

Benjamin Flores de Oliveira nasceu em 20 de dezembro de 1872, em Estrela do Sul, MG. Filho de Joaquim Augusto Flores e Angela Augusta de Oliveira, ficou órfão de mãe ainda em idade tenra. A mãe era "indígena", que não teria aceitado de todo a cultura do branco: "Foi resistente até a sua morte". O pai, que era professor, viu-se sem condições de continuar a criar e educar o filho sozinho; por isso, matriculou-o em um internato (FLORES, 2016).

Benjamin Flores tinha 9 anos de idade quando entrou no Colégio do Caraça, região de Catas Altas. Saiu aos 19. Como se pode inferir do que diz Andrade (2013, p. 168-9), estudar nessa escola era estudar na instituição alçada à condição de lócus de instrução da elite mineira. Ali, os alunos teriam acesso a uma cultura letrada que seria fator de "distinção social" e daria acesso a estratos mais elevados na hierarquia social. Para lá, foram enviados filhos de herdeiros de fazendeiros (que eram, também, donos de forjas e tecelagens, dentre outros negócios). Muitos dos egressos se projetariam no cenário político mineiro, como aqueles de uma família de Itabira cujas gerações estudaram no Colégio do Caraça e governaram sucessivamente o município. Nos anos de 1870-1890, a matrícula incluiu mais de 300 alunos, cada um pagando mensalidades e tendo de gastar com livros, por exemplo. $\mathrm{O}$ custo anual de um aluno chegava a 680 mil réis nos anos de 1870 . A escola foi instalada em 1820 como instituição, cuja instrução se alicerçava na antiguidade clássica; foi a primeira escola privada de Minas Gerais com foco em humanidades. O curso durava sete anos, com até 28 disciplinas. A orientação pedagógica

\footnotetext{
3 A pesquisa subjacente a esse artigo se vincula ao projeto de pesquisa mais amplo Educação, pobreza, política e marginalização: formação de trabalho na nova capital de Minas Gerais, 1909-1947, aprovado pela Fundação de Amparo à Pesquisa do Estado de Minas Gerais e pelo Conselho Nacional de Pesquisa. O texto parte de elementos dados no trabalho de pós-doutorado Escola Profissional Feminina de Belo Horizonte, MG, apresentado na Universidade de Uberaba em 2017, sob orientação do professor doutor José Carlos S. Araujo.
} 
era marcada pelo enciclopedismo. Latim era não só requisito para avançar no curso, mas também fonte do saber. Expressões em latim eram obrigatórias para ornar o discurso. Sabê-lo era base essencial para dominar a chamada língua culta, ou seja, o português ajustado a prescrições gramatical-normativas para correção e uso da linguagem.

Essa base pedagógica fundada na cultura grego-romana “[...] não significava necessariamente a especialização profissional futura”. A preparação que oferecia visava aos exames para entrar no ensino acadêmico; mais que isso, o sentido de estudar no Colégio do Caraça era de classificação social: a escola educava os que "não eram como todos" (ANDRADE, 2013, p. 167), ou seja, como os que não podiam pagar: a pobreza. Em que pese essa pedagogia preparatória para exames, os egressos tinham, também, uma base curricular que lhes permitia atuar como professores primários e secundários, em especial nas disciplinas que envolviam o ensino de línguas, seja latim, português, inglês ou francês.

Talvez por estar ciente dessa formação não profissionalizante é que Joaquim Augusto tenha se preocupado com a ocupação profissional do filho em seus últimos anos no internato. Uma carta de 1891 mostra a preocupação do pai. De imediato, notam-se dificuldades de comunicação entre ambos. Joaquim teve de se valer de uma rede de amigos e parentes em cidades como Formiga, Santo Antonio do Monte, Santa Abadia etc. para ter notícias do filho. Queria saber "[...] qual seria tua sorte em que estado estarias talves soffrendo nessecidades, fóme nudés, estimado ou despresado". A carta que chegou a Benjamin Flores tem data de 2 de abril de 1891 e foi escrita em São d'El Rey, onde o pai havia se encontrado com um padre, que acenou para o futuro profissional do filho. O padre havia perguntado por este e, nas palavras de Joaquim, disse que o "Diretor do Collegio São Francisco" tinha "[...] reservada huma cadeira para ti, e também a Regencia do mesmo Collégio". Nesse sentido, a missiva de Joaquim era para informar dessa possibilidade de emprego e da necessidade de uma resposta com "brevidade", pois o padre estaria "ancioso para saber a tua deliberação". Havia "pretendentes", mas "elle não as cede sem a tua decisão" (FLORES, 1891, s. p.).

A julgar por notícias citando o nome de Benjamin Flores, sua decisão seguiu orientação diferente. Em dezembro de 1892, o jornal Minas Geraes (1892, ed. 238) citou seu nome em texto de chamada para exames preparatórios. Disso se infere sua vontade de se tornar acadêmico. Um ano depois, o jornal informou sobre sua posse no cargo de "praticante supplente" na administração dos Correios, em Ouro Preto (MINAS GERAIS, 1893, ed. 340, p. 5). Em 1894, ele tornou a fazer exames, dessa vez de latim, além de se matricular no Ginásio Mineiro, em Ouro Preto (MINAS GERAIS, 1894, ed. 34). Além de se candidatar aos exames, ele passou a lecionar Latim "segundo o programa de exames", conforme anúncio pelo jornal Minas Gerais (1894, 27 mar. p. 4). Também foi convidado a ser examinador das "alumnas da escola primária do sexo feminino" (MINAS GERAIS, 1895, 27 mar. p. 4).

Em setembro de 1895, ainda como funcionário dos Correios, Benjamin Flores pediu transferência para Belo Horizonte. Seu pedido foi indeferido (MINAS GERAIS, 1895, ed. 247). Mesmo assim, é possível cogitar que vislumbrasse outro futuro para ele na nova capital. Se não fosse como funcionário dos Correios, então teria de ser de outra forma. De fato, ao que tudo indica, ele deixou os Correios entre 1895 e 1896. Em junho de 1896, seu nome aparece no jornal como amanuense (ou seja, copista/escriturário), lotado na terceira seção da Secretaria do Interior, ainda em Ouro Preto (MINAS GERAIS, 20 jun. 1896). Além disso, passou a lecionar Latim no externato de Ouro Preto (MINAS GERAIS, 2 jul. 1896).

O acúmulo de dois empregos deve ter sido consequência dos ganhos como funcionário público. Em um quadro de despesas da Secretaria do Interior no primeiro semestre de 1896, é possível ter uma medida dos salários com base na equipe do internato do Ginásio Mineiro. De ordenado e gratificação, o amanuense ganhava 900 réis (900\$000); o porteiro, 700; um dos professores, 1.500; o médico, 1.800; e o secretário-bibliotecário, 1.800, para ficar em alguns exemplos (MINAS GERAIS, 14 jan 1896, p. 3). Ainda que houvesse possibilidades de 
gratificação, às vezes elas não se concretizavam por determinação superior. Benjamin Flores não recebeu mais de 30 réis que lhe foram atribuídos por ter atuado na Secretaria de Polícia, substituindo um dos oficiais. A Secretaria de Finanças entendeu que não era devida (MINAS GERAIS, 19 out. 1896). Também é provável que a possibilidade de formar família tenha determinado os esforços em dois empregos. Em dezembro de 1896, ele arranjou os papéis para se casar com Thereza de Jesus Carvalho, então com 20 anos de idade (ele tinha 23) (MINAS GERAIS, 17 dez. 1896) ${ }^{4}$.

FIGURA 1: Benjamin Flores e esposa. Thereza e Benjamin tiveram as filhas: Benjamira Flores Arcieri, Dagmar Flores de Carvalho, Eunice Flores, Eliza Flores Pereira, Graci Flores Moura, Maria de Lourdes Flores Horta e Neide Flores; e os filhos Antonio Lorêto Flores, José do Carmo Flores e Moacir da Paz Flores também.

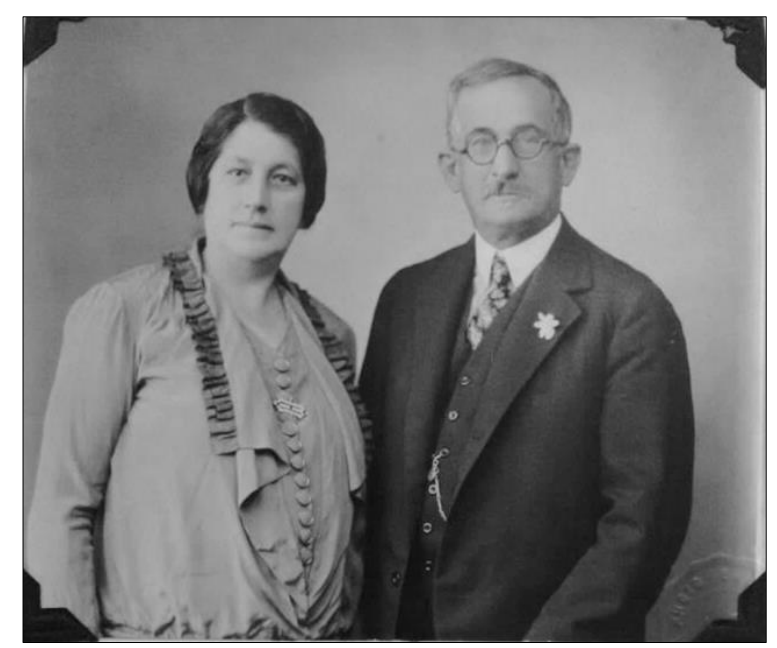

Fonte: Diário Da Tarde (12 maio 1950, s. p.). Acervo de Tereza Cristina Flores Moura — fotógrafo desconhecido.

O sogro de Benjamin Flores, Francisco Pinto, era contínuo da Secretaria de Governo (MINAS GERAIS, 18 dez. 1896). Como tal, teria direito a uma casa na nova capital. Com sua morte em 1897, o direito passou a ser da esposa, que pôde receber a hipoteca a partir de setembro de 1898 (MINAS GERAIS, 7 abr. 1898).

Também Benjamin Flores se viu às voltas com questões de moradia a partir de 1897. Diferentemente da sogra, demandou do poder público o aluguel de "[...] uma das casas velhas em Bello Horizonte” (MINAS GERAIS, 22 set. 1897, p. 1), ao que foi atendido. É curioso que tenha desejado alugar uma casa em vez de comprá-la; mais ainda que tenha preferido uma velha. Uma justificativa plausível seriam seus rendimentos salariais, que não lhe permitiam comprar um imóvel de moradia tão logo se mudasse para a nova capital. De fato, já nos primeiros meses de 1898 ele se viu em dificuldades de pagar todo o aluguel de uma vez. O jornal Minas Gerais (1898, 19 abr.) informou que ele havia requerido pagamento do aluguel em duas vezes. Seu pedido foi não só negado, como replicado com essa recomendação: se o aluguel da casa lhe era caro, então que procurasse outra casa com aluguel barato.

Com efeito, em fevereiro de 1899 ele estava tentando alugar outra casa, do "typo 6, na rua Alfenas" (MINAS GERAIS, 28 fev. 1899, p. 1). Nessa rua, e na Grão Mogol, o poder

\footnotetext{
${ }^{4}$ Curiosamente, um dia após o cartório publicar no jornal os arranjos legais do casamento, o Minas Gerais informou sobre o pedido de licença de quinze dias para cuidar da saúde, que Benjamin Flores havia feito à Secretaria do Interior; o pedido, porém, foi indeferido (MINAS GERAIS, 19 dez. 1896).
} 
público buscou construir casas populares na tentativa de minorar um problema que se anunciava: "[...] déficit de moradias, especialmente para os operários"; afinal, em dezembro de 1897, a capital contava com apenas "500 casas (200 de funcionários públicos)" e serviços urbanos como "iluminação elétrica, abastecimento de água", enquanto a população somava doze mil pessoas. Em agosto, as intenções de Flores já eram de comprar uma casa do governo. Em requerimento, pediu a criação de uma lei que autorizasse lhe vender uma casa do poder público conforme as condições legais para aquisição de imóveis para funcionário público. Ao que indicam as fontes, ele havia adiantado certa quantia a uma firma construtora - Alberto Bressane \& Companhia, que construía as casas populares da rua Alfenas - e quis negociar com o governo (MINAS GERAIS, 15 ago. 1899). O pedido não foi atendido.

Em setembro de 1899, Benjamin Flores ainda residia na casa "typo 6" da "villa Bressane", mas estava insatisfeito. Ao lado de "outros moradores", pediu "[...] abaixamento nos alugueis das casas typo 6 em que residem". De novo, teve seu pedido indeferido (MINAS GERAIS, 20 set. 1899). Além do aluguel elevado, as condições sanitárias deixavam a desejar. No fim de outubro, ele se viu obrigado a requerer a construção de uma latrina na casa onde morava (MINAS GERAIS, 21 out. 1899). Junto com requerimentos listados na mesma nota, seu pedido dá uma medida das condições sanitárias: faltava não só esgoto, mas também água, pois outros moradores pediam ligação da rede d'água em suas casas.

Como se pode inferir desses fatos, as condições de moradia eram dificultosas. A falta de água corrente e de redes de esgoto sanitário dá uma medida do contexto onde estavam: uma cidade planejada em pleno processo de construção, urbanização e expansão territorial com a abertura de loteamentos e construção de vilas residenciais para a classe trabalhadora. Assim, Benjamin Flores deve ter chegado ao seu extremo de tolerância diante de tais condições, pois em dezembro de 1899 apresentou a planta da casa que pretendia construir "em lote suburbano" (MINAS GERAIS, 4 dez. 1899, p. 1). Seu requerimento teve aprovação plena (expedição de alvará). Ao mesmo tempo, adquiriu a casa onde morava na vila Bressane, como se infere de seu pedido de mais prazo para pagá-la (MINAS GERAIS, 17 fev. 1900). Além de adquirir a casa, candidatou-se à compra de lotes "urbanos" e "suburbanos" entre 1898 e 1899 (cf. Minas Gerais, ed. 88, 295 e 311/1898 e 149, 236 e 246/1899).

Os negócios imobiliários de Benjamin Flores se abrem a reflexões, em especial sobre os recursos de que se valeu para comprar imóveis. Afinal, em julho de 1898 havia nascido José Flores, o primogênito; além disso, é provável que tenha tido gastos com o curso de Direito, pois estava em condições de se matricular em 1897 (MINAS GERAIS, 1897, ed. 85). Ao que indicam as fontes, em fevereiro de 1898 ele ainda era amanuense da Secretaria do Interior - e sujeito a não receber integralmente seu salário por descuido da Secretaria de Finanças, conforme se lê em nota do Minas Gerais (1898, 20 set. 102) sobre ressarcimento.

A possibilidade de um segundo emprego como docente — de mais renda — viria só a partir de julho de 1898, após a fundação da Escola Ateneu Mineiro, destinada a preparar seus alunos ao ensino superior. Benjamin Flores esteve à frente da secretária, cuidando da comunicação com a imprensa (e a sociedade belo-horizontina). Além disso, assumiu a função de professor (MINAS GERAIS, 11 jul. 1898). Assim, pode ser que seu envolvimento com esse empreendimento tenha rendido recursos extras que lhe permitiram comprar lotes.

Também pode ser que a compra de lote fosse acessível à classe trabalhadora: operários da construção, comerciários e funcionários públicos, dentre outros. Com efeito, a aquisição de lote na recém-inaugurada capital mineira, mesmo em áreas que já tinham serviços de urbanização (iluminação elétrica e abastecimento de água), foi facilitada pela pouca valorização dos terrenos nos primeiros dez anos. A decisão do primeiro prefeito de "extinguir 
os aglomerados de casebres" nos bairros Alto da Estação (atual Santa Tereza) e Leitão (atual Barro Preto) exigiu vender muitos lotes “[...] para operários à razão de vinte réis o metro quadrado". Depois, houve nova cessão de lotes à venda para funcionários públicos ao preço de cinco mil réis a unidade. Além disso, moradores de Ouro Preto que eram proprietários de imóveis na nova capital se sentiram prejudicados com a cobrança de impostos sobre prédios que detinham em certas áreas. Isso desvalorizava seus imóveis, mesmo que tivessem ganhado lote em áreas suburbanas como compensação. Um comércio ainda precário e a quase inexistência de indústrias os levaram a vender seus lotes a preços ínfimos. Além disso, eram vendidos a particulares e funcionários públicos "lotes contíguos, um gratuito e outro pago mensalmente"; mas tinham prazo-limite "para serem ocupados" (MATOS, 1992, p. 8).

Essas observações dão uma medida de como Benjamin Flores conseguiu investir em lotes mesmo sendo assalariado. As condições da compra, como o pagamento mensal, favoreciam a aquisição a uma população que logo se avolumou: os que foram para a nova capital a fim de trabalhar em sua construção "dentro do prazo exigido por lei". A essa mão de obra, "de baixa qualificação", o estado teve de financiar instalações como hospedarias, pois, como se pode inferir, era "[...] insuficiente o número de moradias e alojamentos coletivos". Os operários, é claro, reagiram erguendo o que lhes era possível erguer: "cafuás", "barracas"; enquanto a prefeitura construía casas de "pau-a-pique, cobertas de zinco" a fim de serem "alugadas a preços módicos" para trabalhadores com família e solteiros (MATOS, 1992, p. 9).

Ante o déficit crescente de moradias - e mais severo para o operariado - , o poder público lançou mãos de outras estratégias: "[...] negociou com particulares a construção de casas populares nas ruas Grão Mogol e Alfenas (100 unidades)" ${ }^{\prime 5}$. Também formalizou a concessão de vantagens para estimular a construção civil: redução de impostos sobre "[...] prédios pertencentes a um mesmo proprietário, destinados a habitação e que não excedessem um certo valor anual na cobrança de aluguéis" (MATOS, 1992, p. 9).

\section{O agente político: eleições e candidaturas}

Nesse contexto de condições precárias de moradia para a classe trabalhadora e de iniciativas do poder público para melhorá-las, Benjamin Flores apresentou sua reação a tal estado de coisas. Em 1911, então como membro do Conselho Deliberativo de belo Horizonte, ele submeteu proposta de mudanças legais para suprir o déficit residencial. As intenções passavam por

[...] tornar o operário proprietário, afim de que tenhamos permanentes os braços necessários a nossas indústrias. Queremos que o funccionarios, ultimamente nomeados, possuam um tecto para não serem victmados pelos alugueis que lhes estão absorvendo $50 \%$ dos vencimentos. Almejamos finalmente construcção de villas para podermos eliminar as infectas e anti-hyginenicas cafuas e os cortiços. (FLORES, 1911, p. 2).

Tais ideias vinham de quem conhecia bem as condições de moradia dos trabalhadores: faltava água e esgoto; a mortalidade infantil se destacava (MATOS, 1992). Em 1899,

\footnotetext{
${ }^{5}$ A casa que Benjamin Flores adquiriu era de Candido Botelho, conforme nota publicada pelo Minas Gerais (6 set. 1899). E provável que ele conhecesse o vendedor, pois Botelho era secretário do externato de Ouro Preto, onde Flores fez exames e, depois, assumiu a cadeira de Latim, antes de se mudar para Belo Horizonte. Voltaram a se encontrar na nova capital, no Ginásio Mineiro.
} 
Benjamin Flores passou a ser professor no Ginásio Mineiro, ocupação que talvez fosse incompatível com a de amanuense. Além disso, a remuneração era maior, sem contar que lhe dava mais projeção na sociedade que se formava. Sua faceta de cidadão atento a problemas sociais como moradia do operariado começou a aparecer nos jornais em 1898, ano de sua aprovação no concurso para a cadeira de Latim no Ginásio Mineiro da capital. Houve notícias de visita à sede do governo mineiro, como a que fez, em 1898, com militares e senadores (MINAS GERAIS, 20 set. 1898); e notícias sobre seus contatos no meio empresarial, como quando acompanhou um empresário da mineração para avaliar jazidas de manganês no perímetro urbano da capital (DIÁRIO DE MINAS, 14 maio 1899). Como conselheiro deliberativo, fez contatos com autoridades mais elevadas na hierarquia política, a exemplo de senadores e deputados como Fidélis Reis: político importante para a formação do ensino profissional em Minas Gerais. O nome de Flores apareceu associado a visitas à presidência da República em 1916 (JORNAL DO COMMERCIO, 29 jan. 1916).

Com efeito, a política atraiu o interesse e os esforços de Benjamin Flores, tanto quanto a educação. Parece ter visto no campo político uma possibilidade de apresentar e desenvolver projetos para melhorar as condições de vida da classe trabalhadora e a vida na cidade, desenvolver a indústria e o comércio, dentre outros pontos. Essa impressão se justifica, por exemplo, na menção, em 1903, ao seu nome como candidato ao senado mineiro (O PHAROL, 14 mar. 1903) e, no mês seguinte, como membro de junta apuradora de votos, formada em um processo de contestação do pleito (JORNAL DO BRASIL, 4 abr. 1903). Uma vez malsucedido na eleição para senador, restava a Câmara Municipal, sobretudo com a preferência à candidatura de professores. Em 1907, ele foi eleito vereador (JORNAL DO BRASIL, 2 nov. 1907).

Contudo, a preferência por professores para ocupar a Câmara como vereador não teve efeito no pleito para deputado: o resultado da votação de 1909, nos distritos de Belo Horizonte, deu uma medida da popularidade de Benjamin Flores: teve 723 votos, enquanto o candidato mais votado obteve 7.429 (O PHAROL, 14 mar. 1909). Com a derrota no pleito do primeiro distrito, ele se alinhou como candidato a deputado pelo quinto distrito. Estava, então, entre os residentes dessa região eleitoral que ali labutavam em prol de melhorias. Dentre os atributos que o qualificavam, estavam sua condição de "professor emerito muito relacionado", "ter sólidos elementos a seu favor, capazes de elegel-o, mesmo fôra da chapa" (O PHAROL, 14 mar. 1903, p. 1). De novo Benjamin Flores não se elegeu. Também não conseguiu votos suficientes para, em 1915, eleger-se deputado, ainda pelo quinto distrito (O PAIZ, 2 fev. 1915), e senador, nas eleições de 1927 (A TRIBUNA, 13 mar. 1927).

Desses fracassos se infere que Benjamin Flores parece ter sido um político impopular. Seus mandatos eletivos não foram além da Câmara de Vereadores. Por isso não é de estranhar que seu nome tenha sido cogitado como suscetível de dar lugar a outro na chapa formada em 1912, para o quinto distrito (GAZETA DE NOTÍCIAS, 14 maio 1909). Além disso, havia quem visse nele um defensor de causas próprias. A condição dele, nos termos da imprensa jornal, era a de um "[...] operoso edil que abarrota[va] todos os annos o orçamento com emendas sobre favores pessoaes, as quaes, felizmente não lograram nunca approvação" (O PAIZ, 17 fev. 1915, p. 6) Os críticos viam professores de instituições de ensino superior estaduais e federais como sem competência para a política, por isso cogitavam mudanças na política de Minas Gerais.

\section{O agente público: conselheiro municipal}


Além de tentar se eleger — e de ser eleito — para funções políticas na Câmara de Vereadores e na de Deputados, bem como no Senado, Benjamin Flores se elegeu para a vaga no Conselho Deliberativo ${ }^{6}$ de Belo Horizonte; e foi como conselheiro que teve condições de propor projetos. Sua ação se fez notar em 1909, quando declarou e justificou, em carta aberta, sua adesão ao grupo de apoiadores do então candidato à presidência da República, Hermes da Fonseca. Com sua atitude, o conselho não seria representado na Convenção Nacional de lançamento da candidatura de Rui Barbosa. A carta teria sido bastante comentada (GAZETA DE NOTÍCIAS, 29 abr. 1909). Também polêmica foi sua proposta de emenda ao orçamento da prefeitura em prol de gratificação aos conselheiros. O jornal O Pharol (5 out. 1912) se referiu a rumores de que a proposta seria combatida e cairia logo ao Congresso Mineiro.

As propostas de Benjamin Flores como conselheiro nem sempre foram benquistas. Houve casos em que ele se viu obrigado, pela repercussão na imprensa, a justificar seus projetos. Em um deles, a justificativa foi feita ao $O$ Estado de Minas e replicada em $O$ Paiz, do Rio de Janeiro. Este último jornal - que tinha sucursal em Belo Horizonte - chamou de "desastroso" o projeto de Flores que presumia alargar a avenida Afonso Pena para dar espaço a "construcções particulares". O problema residia no alargamento, ou seja, em tirar "uma larga faixa" do parque municipal (O PAIZ, 11 fev. 1913, p. 5).

Em que pesem as críticas aos projetos que Benjamin Flores apresentou ao Conselho Deliberativo, pode-se perceber continuidade em suas convicções sociais e na atenção a demandas do povo de Belo Horizonte. Um projeto seu de 1912 propôs criar uma diretoria de higiene municipal para cuidar da saúde publica. Tal cuidado incidiria, dentre outros pontos, na fiscalização de alimentos e em visita a residências "particulares e collectivas" (JORNAL DO COMMERCIO, 17 set. 1912, p. 12). Como um tipo de contraste com as condições de saúde e higiene em áreas onde havia mortalidade infantil elevada, Flores viu seu projeto de assistência à infância se submeter aos ideais e às prescrições eugênicas que permearam discursos e ações de autoridades públicas e médicos em Belo Horizonte na primeira República. Essa submissão ficou patente em emenda que presumia "[...] organizar, annualmente, um concurso de robustez entre crianças de um anno de idade"; "às dez primeiras na classificaçao receberiam premios pecuniarios" (CORREIO PAULISTANO, 6 out. 1913, p. 4).

As ideias que ele apresentou em 1911, para ajudar a resolver o problema de moradia, reverberou em seus mandatos no conselho. Em 1914, foi apresentada, para ser avaliada, a proposta de conceder "[...] auxílio ás empresas industriaes e commerciais e a proprietarios de fabricas e officinas para construcçaes de casas para operarios". Além da moradia, as formas de locomoção urbana foram preocupação para Flores, que indicou ao conselho a proposta de "[...] creação de dous trens de suburbio, com passagens reduzidas, entre esta cidade e Santa Luzia do Rio das Velhas" (JORNAL DO COMMERCIO, 3 out. 1914, p. 2). A ideia era replicar algo que já ocorria em relação à capital e Sabará. Haveria um trem matutino e um vespertino (O PAIZ, 4 out. 1914).

Benjamin Flores reconheceu como importante para o "incremento ao progresso do município" a criação de órgãos de representação institucional. Para tanto, apresentou projeto

6 “O Poder Legislativo Municipal, foi instalado em Belo Horizonte de forma embrionária, sob a forma de um Conselho Deliberativo, dois anos após a transferência da Capital para a Cidade de Minas. A lei n 275 de 12 de setembro de 1899, instituiu na Capital um Conselho Deliberativo composto de sete membros eleitos pelo povo. A este Conselho competia votar os impostos e decretar as despesas e serviços peculiares da administração da Capital. As funções executivas do governo da Cidade de Minas continuaram a ser exercidas pelo prefeito, então nomeado pelo Presidente do Estado. O Decreto Estadual 9.768 de novembro de 1930, de acordo com o art. 11 do decreto federal $\mathrm{n}^{\circ}$ 19.398 de 1930 confirmou a dissolução das câmaras municipais e Conselhos Deliberativos do Estado. As câmaras municipais se transformaram em prefeituras até a reorganização constitucional do Estado. Nos municípios, de acordo com o decreto estadual 9.847 de 2 de fevereiro de 1931, competia ao prefeito a administração municipal exercendo as funções do poder executivo e do legislativo. As prefeituras respondiam à Secretaria do Interior. E a Prefeitura de Belo Horizonte respondia diretamente ao Presidente do Estado" (ARQUIVO PÚBLICO MINEIRO, 2014, on-line). 
de lei nesse sentido (JORNAL DO COMMERCIO, 17 set. 1912, p. 2). Além de estimular a formação de associações de classe e categoria profissional, ele se viu na condição de partícipe de algumas. Seu estímulo reverberou na criação de associação para o bairro Barro Preto, onde parte relevante da classe trabalhadora estabeleceu moradia. Não por acaso, ele figuraria como seu "presidente honorario" (JORNAL DO COMMERCIO, 4 nov. 1916, p. 7). Daí vem sua projeção em meio ao operariado, a ponto de ser convidado a representar a confederação dos operários de Minas Gerais em congresso nacional. Além disso, a função de conselheiro e fiscal parece ter colado em sua personalidade. Ele, que já era membro do conselho deliberativo do centro operário da capital (JORNAL DO COMMERCIO, 24 out. 1912), passou a ser membro do conselho fiscal de uma associação mutuária de amparo a famílias. Ao lado de outros, aprovava as contas da associação (O PAIZ, 3 ago. 1913). É curioso, porém, que Flores, docente e agente público ativo, tenha atuado em prol de uma associação de docentes, não em seus primeiros anos como professor, mas só quase trinta anos depois. Seus esforços para ajudar a constituir tal associação datam de 1928, com reunião de professores para aprovar os estatutos da associação (CORREIO DA MANHÃ, 16 jun. 1928).

$\mathrm{O}$ alcance dos projetos de Benjamin Flores no conselho se estendeu à economia. Ele se preocupou com produtores rurais, ao propor um projeto de lei que prescrevesse a realização anual de uma feira em que tais produtores pudessem expor e comercializar sua produção $(\mathrm{O}$ PAIZ, 5 out. 1912). Também o comércio preocupou Flores. Ele reconhecia que a capital havia se tornado "o maior centro commercial e industrial" do estado, pois reunia mais de "seiscentas casas commerciais e cincoenta e oito fabricas diversas" (O PAIZ, 17 fev. 1916, p. 2). Para isso, seria útil a abertura de uma agência do Banco Brasil. Em prol desse projeto, assinou texto publicado em $O$ Paiz sobre a indicação, aprovada, de abertura da agência bancária.

Ao mesmo tempo em que atuava como agente público, propondo projetos para Belo Horizonte, Benjamin Flores atuou como agente educacional propondo medidas e desenvolvendo projetos na área do ensino, dentre os quais a criação de escolas.

\section{$O$ agente educacional: professor, conselheiro do ensino e dono de escola}

Com efeito, após assumir como docente de Latim do Ginásio Mineiro, em 1899, cabe lembrar, Benjamin Flores não ficou alheio a outras instâncias do ensino, que não fosse a sala de aula. Em 1905, passou a compor o Conselho Superior de Instrução Pública, cujo presidente era então Delfim Moreira, secretário do Interior (O PHAROL, 16 jun. 1905). Essa posição o credenciaria a atuar no campo da inspeção, quando foi designado pelo Ministério da Justiça e Negócios Interiores para fiscalizar exames em escolas como o Ginásio de Itajubá (JORNAL DO COMMERCIO, 3 dez. 1916, p. 7). No ano seguinte, foi "commissionado pelo govêrno federal" para avaliar a Academia do Comércio e expor suas impressões em um relatório (A UNIÃO, 10 nov. 1917, p. 1).

A atuação de Benjamin Flores no Ginásio Mineiro foi além da docência. Três anos após sua criação, a escola se viu na iminência de ser desativada, porque o número de matrículas não estava justificando sua manutenção. Diante disso, um grupo de professores, dentre os quais Benjamin Flores, reuniu-se com o reitor a fim de delinear saídas para a situação que motivou a possibilidade de fechamento (O PAIZ, 15 ago. 1912).

Mesmo como professor concursado e atuante no Ginásio Mineiro e membro ativo do conselho deliberativo, Benjamin Flores conseguiu estabelecer condições para não só lecionar em outras escolas, como também fundar escolas em Belo Horizonte. Em 1912, ele criou a Escola do Comércio, em associação com mais duas pessoas, dentre as quais um senador (O 
PHAROL, 15 ago. 1912). Em certo sentido, essa iniciativa convergia com seus esforços em prol do comércio como conselheiro. Dois anos depois, juntou-se a outros para criar a Escola de Agronomia e Veterinária (JORNAL DO COMMERCIO, 11 ago. 1914). Tal escola, supostamente, não ficou isenta de problemas financeiros, pois Flores — professor da instituição - apresentou ao Conselho Deliberativo um projeto que presumia apoio financeiro (DIARIO DE PERNAMBUCO, $1^{\circ}$ fev. 1915).

Contudo, a iniciativa de maior projeção de Benjamin Flores foi a criação de uma escola profissional voltada para mulheres. Seu interesse por essa modalidade de ensino foi manifestado já em 1909. Por indicação dele no Conselho Deliberativo, esse órgão se dirigiu ao presidente da República com mensagem de "applausos" e "felicitações" pelo decreto que instituiu a "[...] creação de escolas profissionaes em todas as capitaes" (CORREIO PAULISTANO, 10 out. 1909, p. 2). Dessa indicação se inferem motivações de Benjamin Flores para participar do congresso sobre ensino profissional em 1911.

Há incertezas sobre a data de criação da Escola Profissional Feminina. Barreto (1950, p. 217) diz que “[...] em 1913 o professor Benjamin Flores fundou a Escola Profissional Feminina". Na imprensa de São Paulo há referências à escola em notícia de março de 1913 (CORREIO PAULISTANO, 12 mar. 1913, p. 3). O Anuário de Belo Horizonte (BELO HORIZONTE, 1953, p. 151) confirma Barreto: "Em 1913 o professor Benjamin Flores fundou a Escola Profissional Feminina”. Relatórios do Ministério da Agricultura apresentados ao presidente da República pelo ministro de Estado da Agricultura, Indústria e Comércio Miguel Calmon du Pin e Almeida (1925, p. 640) consta que a "Escola Profissional Feminina de Bello Horizonte - [foi] Fundada em 1917'. Para Gomes e Chamon (2010), é provável que Flores tenha considerado como ano de fundação aquele em que o diploma de sua escola foi reconhecido pelo governo mineiro: 1920. Os anos anteriores (1913-1919) teriam sido desconsiderados como parte da história da escola porque esta não era "oficializada". "Assim 1919 figuraria como o marco zero da escola e os anos anteriores, talvez anos incertos, movidos pela estruturação da escola, seriam relegados ao esquecimento" (p. 11). Dada a falta de mais registros materiais da existência da escola à época, parece plausível o suficiente a hipótese desses autores. Em edição do Minas Geraes de 1920 se lê que a escola foi

[...] fundada em agosto de 1919, conforme consta no jornal Minas Gerais do referido mês e ano [...] como instituição de ensino technico e profissional, com duração indefinida, que tem por fim preparar suas alumnas, ministrando-lhes solidos conhecimentos de uma arte ou profissão, de modo a tornal-as na luta pela vida, uteis a si e á pátria. (MINAS GERAES, 23 jan. 1920, p. 4)

Incertezas de data à parte, fica clara a dinâmica de Benjamin Flores como agente público e agente educacional, sem contar outras atividades como a participação de associações, a fiscalização e o cuidado da família, cada vez mais numerosa. Surpreende sua capacidade de administrar a vida particular e pública ao transitar por contextos distintos, e de sustentar uma escola com propósito tão arrojado, ou seja, de incluir as mulheres no movimento de modernização e de esforços em prol do progresso.

Com efeito, esse ideal de ensino reverberou na trajetória de vida da egressa Maria Celme Caetano. Filha de mãe que tinha hanseníase, ela era "convidada" a deixar as escolas 
onde se matriculava, tão logo a direção descobria a condição da mãe. Ela era parte de um grupo de excluídos de certas instâncias sociais e sujeitados aos "meios acionados pela sociedade" para "categorizar as pessoas" (GOFFMAN, 1975, p. 73); era estigmatizada por ter "[...] atributos considerados como comuns e naturais, para os membros [...]" das eventuais categorias, a exemplo de quem tinha hanseníase. Nos anos de 1930, tal mentalidade de intolerância “[...] inferiu a crença de que era necessário, isolar, banir, excluir e marginalizar os doentes [...] o isolamento compulsório como à única medida profilática capaz de coibir o crescimento da hanseníase no Brasil" (SILVA, 2009, p. 70).

A escola de Benjamin Flores foi das poucas instituições escolares — para não dizer a única - a aceitar Maria Celme como discente regular, e que conquistaria seu diploma de normalista profissional em 1946. Ela contou sua experiência na escola assim:

[...] fui colocada numa outra escola: "Escola Profissional Feminina" na Avenida Amazonas, esquina com Tamoios, do Professor: Benjamin Flores. Este era espírita e as aulas voltadas para as línguas: Tupi Guarani, Grego e Latim. Programadas para todos os dias eram apenas para que as alunas permanecessem em classe e em silêncio. Não havia a intenção de serem ensinadas. $\mathrm{O}$ próprio professor Flores era $\mathrm{o}$ palestrante. Falava todo o tempo sobre as línguas. Era bem velho. (CAETANO, 2011, p. 35)

Em que pese o tom de crítica da ex-aluna às aulas de línguas do professor Benjamin Flores — já "bem velho" — , convém registrar que a atuação dele na escola se estendia a atividades diversas: ia da administração escolar à docência, passando pela escrituração documental.

FIGURA 3. Benjamin Flores, em seu gabinete de trabalho na Escola profissional Feminina

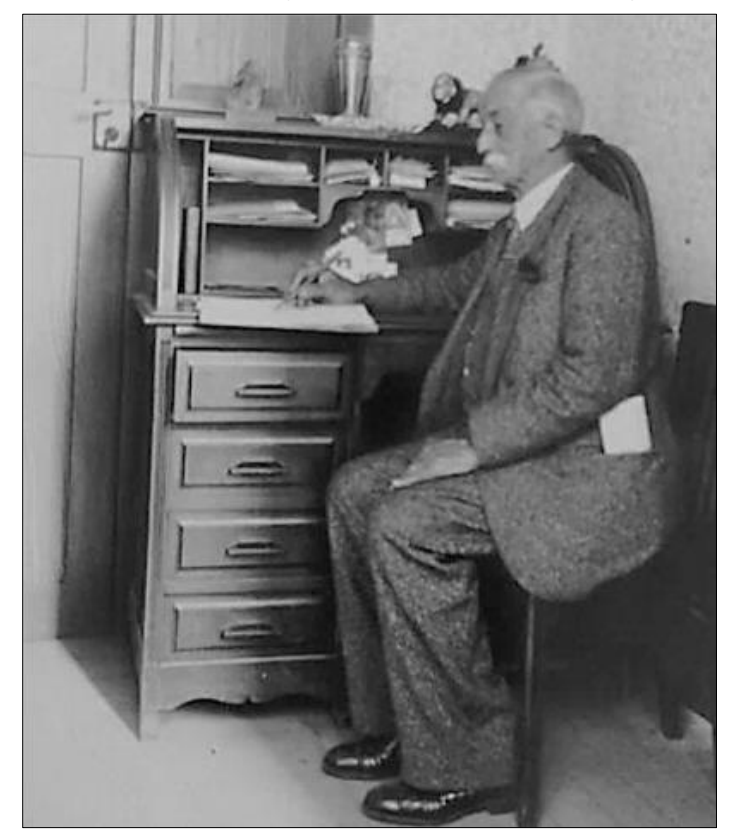

Fonte: acervo de Tereza Cristina Flores Moura - Autoria da fotografia: não identificada

Tal escrituração ia de formulários para apresentar resultados de exames a requerimentos ao poder público no tocante à escola. Quando não eram escritos por Benjamin 
Flores - como os requerimentos — os documentos levavam sua assinatura e seu visto indicando a fidelidade do documento, por exemplo, datilografado, com original manuscrito. Sua leitura era minuciosa, como se pode inferir da correção que fez em trecho de um relatório submetido ao "Ex. Sr. Dr. Secretário da Segurança" no documento datilografado (FIG. 2).

FIGURA 2: Recorte de relatório da Escola Profissional feminina, janeiro de 1930

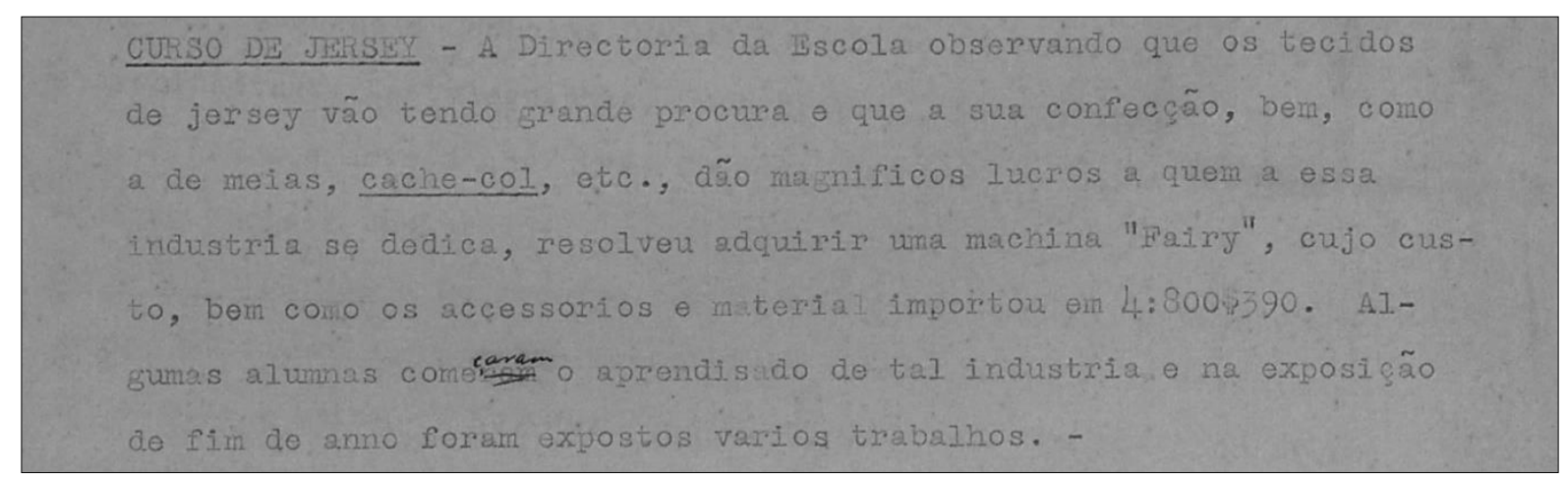

Note-se o descuido entre "comeram" - o datilografado - e o que era no manuscrito - começaram. Supostamente, o relatório foi encaminhado com tais emendas, pois Benjamin Flores o assinou.

Fonte: Arquivo Público Mineiro

Benjamin Flores se aposentou como professor, do Ginásio Mineiro, em 1931. Estava com quase 60 anos de idade (DIÁRIO DA TARDE, 12 maio 1950, s. p.). Do que se pode inferir das fontes levantadas, após se aposentar ele passou a se dedicar à escola profissional até os últimos anos de vida.

\section{O homem: pesar pela morte de Benjamin Flores}

A morte de Benjamin Flores, em maio de 1950, foi ressaltada com pesar pela imprensa mineira, sobretudo com menções ao trabalho dele no ensino. O Diário de Minas, dentre outros jornais, noticiou a morte na edição de 12 de maio, com esta manchete: "Desaparece querida figura do magistério mineiro", seguida deste texto:

A notícia do falecimento do prof. Benjamin Flores, ontem ocorrido na capital, repercutiu intensamente nos diversos círculos sociais da cidade e no interior. Filho de tradicional família mineira, tornou-se depois, chefe de outra numerosa e digna, cujos membros estão radicados em Minas, em diversos setores. A constante na vida do mestre em Minas acaba de perder foi a vocação para o magisterio. Dai a sua dedicação ás novas gerações o seu amor a cultura e a sua inteireza de caráter. Desde cedo, dedicou-se ele á missão de ensinar e educar, tendo deixado mesmo o curso de medicina que estava fazendo para se entregar exclusivamente ao magisterio. Com a sua inteligencia e esforço fundou numerosos institutos de ensino e dirigiu outros, a saber: Externato Ouro Pretano, em Ouro Preto; Ateneu Mineiro, nesta capital, Escola de Comercio de Belo Horizonte, Escola Mineira de Agronomia e Veterinaria desta capital; Escola Profissional Feminina de Belo Horizonte, cuja direção ainda exercia. [...] Figura largamente conhecida em nossos meios educacionais e em nossa sociedade, era o extinto muito estimado pelas suas qualidades humanas, as quais se aliavam 
grandes predicados de inteligencia e cultura. Sua vida está intimamente ligada ao desenvolvimento do ensino em Minas, como o atestam as suas notas biograficas, pelas quais se tem uma ideia de seus longos e fecundos trabalhos. (DIÁRIO DE MINAS, 12 maio 1950, s. p.)

O texto de certo José Clemente publicado no Minas Gerais dá uma medida de como era Benjamin Flores no dia a dia da vida pública e de sua importância para Belo Horizonte:

Belo Horizonte está ficando sem suas figuras tradicionais. É inevitavel essa baixa. Agora, morre o professor Benjamin Flores. Tinha sua vida ligada á capital e ao povo. Professor, privou com gerações de moços. Legislador municipal, viveu em contacto direto com a população que o elegiu seguidamente para o Conselho Deliberativo, para que ele trabalhasse pelos seus interesses quando o representante do povo tinha de sacrificar o tempo destinado ás suas obrigações ordinárias, para servir á capital, sem qualquer remuneração. Benjamin Flores sempre foi um homem ocupadissimo. Trabalhava sem cessar. Apesar disso, candidatava-se ao Conselho, dispondo-se a servir á cidade, que lhe deve muito. Foi um incentivador de grandes empreendimentos, sobretudo, na esfera cultural e educacional. [...] Benjamim Flores via, através do futuro, a necessidade que a capital ter de um estabelecimento daquela natureza, como instrumento de cooperação social. Deu todas as suas energias á Escola que passou momentos dificeis, mas triunfou, impondo-se ao meio não somente como estabelecimento de ensino, mas como uma das chaves de solução dos problemas sociais, com a valorização da capacidade do trabalho das jovens mineiras. Ilustrou a mocidade, serviu a seu povo e trabalhou pela sua terra. Fez isso, sem queixar cansaço, durante uma existencia de quase oitenta anos. E para morrer pobre. Nunca viamos parado. $\mathrm{Na}$ rua, sempre apressado, cheio de embrulhos. Não podia parar, para não perder o horario de suas obrigações. Não tinha chefes, mas de proprio se impusera a disciplina de cumprir rigorosamente seus deveres, respeitando os horarios. Era uma figura original de lutador, de um genero que não existe mais. (CLEMENTE, 1950, s. p.)

A importância de Benjamin Flores se projetou na Assembleia de Minas. O deputado Julio de Carvalho pediu voto de pesar à família dele. Em seu pedido, destaca-se o reconhecimento do trabalho prestado por ele à sociedade belo-horizontina. Vários deputados, de partidos distintos, discursaram. Lima Guimarães, que havia sido aluno de Benjamin Flores, expressou seus sentimentos nestes termos:

Foi meu mestre, nos tempos do Ginásio. Conheço a sua dedicação ao ensino, pois teve toda a sua vida devotada ao aprimoramento da mocidade, e, ainda depois de velho, depois de uma justa aposentadoria, pelos seus relevantes serviços prestados á educação no Estado, o seu espirito sempre novo se dedicava ainda ao ensino da mocidade. Assim é que fundou a Escola profissional Feminina [...] Assim, com o falecimento do prof. Benjamin Flores o magistério publico perdeu um de seus elementos de relevo e Minas um de seus 
grandes professores. Pelo P. T. B.; associo-me ás homenagens que esta Casa presta á memória do prof. Benjamin Flores. (DIÁRIO DA ASSEMBLEIA, 13 maio 1950, s. p.)

O deputado Juarez de Souza Carmo externou sua reação ao falecimento assim:

As homenagens prestadas pela Assembléia á memória do prof. Benjamin Flores são, sem duvida, as mais justas e merecidas. Dedicou o prof. Benjamin Flores toda a atividade de sua vida ao ensino, prestando assim imenso serviço ao nosso Estado. [...] Vida inteira dedicada á mais nobilitante das causas, tornou-se um benemérito e, pois, é com o mais profundo pesar que a bancada do Partido Republicano, em cujo nome falo, recebeu a infausta noticia do seu passamento, solidarizando-se com as homenagens que neste instante são prestadas á sua inolvidável memória. (DIÁRIO DA ASSEMBLEIA, 13 maio 1950, s. p.)

A tônica dos discursos foi o trabalho de Benjamin Flores no ensino; mas destaca-se sua preocupação com a classe desfavorecida. A homenagem póstuma (a que o falecimento tende a motivar) parece contrastar com os últimos desejos dele, enumerados de próprio punho já na iminência da morte:

Ultima vontade $-1^{\circ}$ Enterro de $3^{\mathrm{a}}$ classe. $2^{\circ}$ Nada de convite, nem pela imprensa, nem pelo radio, nem nas vitrinas, nem pessoal. $3^{\circ} \mathrm{Nada}$ de luto que nada significa. $4^{\circ}$ Nada de missa de $7^{\circ}$ e de $30^{\circ}$ dias ou se disserem nada de convite pela imprensa. $5^{\circ}$ Não forneçam dados sobre minha pessoa para publicarem na imprensa. $6^{\circ} \mathrm{Si}$ o governo quizer, como homenagem, dar meu nome a alguma escola, grupo ou rua, dirijam um oficio em nome do morto recusando a homenagem visto em vida, apesar dos serviços prestados, não ter merecido a mínima consideração dos poderes públicos. (FLORES, s. d)

Como se lê, o sexto pedido tem certo tom de dissabor relativo ao poder público: o de não reconhecer o trabalho dele em vida. Benjamin Flores foi incisivo: recusou o reconhecimento póstumo pelo governo estadual e municipal. Talvez tenha esperado mais do que conseguiu angariar do poder público, tendo em vista seus esforços em um projeto de ensino que não era para o futuro necessariamente. Flores vislumbrou uma meta a ser cumprida pela sua escola no exato presente da instituição e de seu fundador e administrador, no presente de uma capital que se erguia de forma planejada e que buscava se consolidar como modelo de cidade moderna para o país.

\section{Considerações finais}

A compreensão que este estudo buscou construir tem incidência nos antecedentes histórico-sociais e nos atributos pessoais de Benjamin Flores em Belo Horizonte para levar adiante um projeto de ensino que foi a fundação e a sustentação da Escola Profissional Feminina. Também sensíveis ao processo de modernização em Minas Gerais, outros mineiros discursaram em prol do ensino profissional das mulheres da nova capital de Minas Gerais; mas foi Flores que tomou medidas práticas, que foi do discurso, à sua concretização objetiva. 
A compreensão histórica aqui construída delineia essa constatação: a abertura de uma escola de formação profissional para mulheres foi o ápice de um processo de apreensão de uma realidade social que se formava, de compreensão das demandas sociais e culturais que se impunham à sociedade belo-horizontina, sobretudo a uma população operária que se avolumou, justamente, para construir a capital. Daí a preocupação de Benjamin Flores com as condições de moradia dessa classe, com assistência à sua prole, com o estímulo à sua organização institucional-representativa em forma de associações, dentre outras. Sua atuação, nesse sentido, fez-se notar em sua condição de membro do Conselho Deliberativo e, é provável, como vereador. Ao mesmo tempo, sua condição de professor convicto parece ter sido uma via para que projetasse outras formas de suprir outras demandas da população que ele conhecia bem.

Com efeito, na abertura de escolas profissionalizantes, Benjamin Flores parece ter vislumbrado formas de ampliar sua atuação como agente público. Sua iniciativa primeira nesse sentido se voltou à formação profissional para o comércio, pois viu essa vertente da economia se projetar em Belo Horizonte. Sobretudo, ele viu não só comércio, mas também a indústria como espaço de trabalho para a mulher; e é nesse ponto que sua ação se destaca. Em certo sentido, como homem atento ao seu tempo e ao seu espaço, Benjamin Flores entendeu que ofertar outras possibilidades de desenvolvimento profissional para mulheres na esfera pública era, de fato, fazer da nova capital mineira o símbolo da modernização urbana do país. Belo Horizonte não poderia ser capital modelo para a República brasileira, se a população feminina continuasse na condição de submissão e restrição à esfera do privado, se não se integrasse à Republica.

A escola normal e de formação profissional que Benjamin Flores sustentou enquanto pôde, criou condições para a inserção da mulher na esfera pública e no trabalho, ao oportunizar que ocupassem funções como a de professora, secretária, modista, florista e costureira ou manejasse máquinas da indústria do vestuário e da tecelagem. A escola foi uma via de profissionalização das mulheres, de modo que pudessem se apresentar à capital como competentes para desempenhar papéis e ocupar posições que tendiam a ser marcados pela presença de homens.

\section{Referências}

ALMEIDA, Miguel Calmon du Pin e. Relatórios do Ministério da Agricultura apresentados ao presidente da República dos Estados Unidos do Brasil pelo ministro de Estado da Agricultura, Indústria e Comércio. 1925.

ANDRADE, Mariza Guerra. Colégio do Caraça: a formação escolar e a formação das elites; In: LAGE, Maria E.; VILlALTA, Luiz C. A província de Minas, 2. Belo Horizonte: Autêntica, 2013, p. 161-80.

ARQUIVO PÚBLICO MINEIRO. Inventário do fundo Conselho Deliberativo de Belo Horizonte. Belo Horizonte, MG, mar. de 2014, p. 4. Disponível em http://www.siaapm.cultura.mg.gov.br/acervo/fundos_colecoes/CDBH/INVENTARIO_DO_FUND O_CONSELHO_DELIBERATIVO_DE_BH.pdf. Acesso em: 28 mar. 2019.

BARRETO, Abílio. Resumo histórico de Belo Horizonte - 1701-1947. Belo Horizonte: Imprensa Oficial, 1950.

BELO HORIZONTE. Anuário de Belo Horizonte v. 1, ano 1. Belo Horizonte 1953. 
CAETANO, Maria Celme Ribeiro. A saga dos Ribeiro. Clube de Autores, 2011.

CONGRESSO BRASILEIRO DE INSTRUÇÃO PRIMÁRIA E SECUNDÁRIA, 2., 1912, Belo Horizonte. Anais... Belo Horizonte: Imprensa Oficial do Estado de Minas Gerais, 1912.

GOFFMAN, E. Estigma. Notas sobre a manipulação deteriorada. Rio do Janeiro: Zahar, 1975.

GOMES, Warley A.; CHAMON, C. S. Entre o trabalho, a escola e o lar: o caso da Escola Profissional Feminina de Belo Horizonte. In: SEMINÁRIO NACIONAL DE EDUCAÇÃO PROFISSIONAL E TECNOLÓGICA, 2., Belo Horizonte, 2010.

MATOS, Ralfo Edmundo S. Evolução urbana e formação econômica de Belo Horizonte. texto para discussão n. 4, CEDEPLAR/UFMG (Datilografado e trechos escaneados da edição original em papel). Março de 1992. Disponível em http://www.cedeplar.ufmg.br/pesquisas/td/TD\%2064.pdf. Acesso em: 28 mar. 2018.

ROCHA, Marlos Bessa Mendes da. A lei brasileira de ensino Rivadávia Corrêa (1911): paradoxo de um certo liberalismo. Educ. rev., Belo Horizonte , v. 28, n. 3, p. 219-39, set. 2012. Disponível em http://www.scielo.br/scielo.php?script=sci_arttext\&pid=S0102$46982012000300011 \& \operatorname{lng}=\mathrm{en} \& n r m=$ iso. Acesso em: 3 fev. 2017.

SILVA, Rita Cristina Lima Lages e. O ensino de Francês em Minas Gerais nas primeiras décadas do século XIX: os sujeitos escolares e a configuração de uma disciplina. Currículo sem Fronteiras, v. 9, n. 1, p. 91-102, jan./jun. 2009.

\section{Fontes orais}

CAETANO, Maria Celme Ribeiro. Belo Horizonte, MG, dia de mês de ano. Arquivo de mp3 63 minutos). Entrevista concedida a Betânia Laterza Ribeiro na residência da entrevistada.

FLORES, Teresa Cristina. Belo Horizonte, MG. Arquivo de mp3 (60 minutos). Entrevista concedida a Betânia Laterza Ribeiro na residência da entrevistada.

\section{Fontes manuscritas}

FLORES, Joaquim. Carta a Benjamin Flores. Novembro de 1891, manuscrito, 2 folhas. Acervo de Thereza Cristina Flores.

FLORES, Benjamin Flores. [Pedido de última vontade]. S. d. [1950], manuscrito, 1 folhas. Acervo de Thereza Cristina Flores.

\section{Fontes jornalísticas}

A TRIBUNA. São João d'El Rey, MG, 13 mar. 1927.

A UNIÃO. Rio de Janeiro, RJ, 10 nov. 1917.

CLEMENTE, José. Uma figura tradicional. Minas Gerais, Belo Horizonte, MG, 13 de maio de 1950. 
CORREIO DA MANHÃ. Rio de Janeiro, RJ, 16 jun. 1928.

CORREIO PAULISTANO. São Paulo, SP, 10 out. 1909, 12 mar. 1913, 6 out. 1913.

DIÁRIO DA ASSEMBLÉIA. Belo Horizonte, MG, 13 maio 1950.

DIÁRIO DA TARDE. Belo Horizonte, MG, 12 maio 1950.

DIARIO DE PERNAMBUCO. Recife, PE, $1^{\circ}$ fev. 1915.

FLORES, Benjamin. Bello Horizonte, casas para alugar. O Pharol, Juiz de Fora, MG, 9 fev. 1911.

GAZETA DE NOTÍCIAS. Rio de Janeiro, RJ, 14 maio 1909 e 29 abr. 1909.

JORNAL DO BRASIL. Rio de Janeiro, RJ, 4 abr. 1903, 2 nov. 1907.

JORNAL DO COMMERCIO. Rio de Janeiro, RJ, 17 set. 1912, 24 out. 1912, 11 ago. 1914, 3 out. 1914, 4 nov. 1916, 29 jan. 1916, 19 nov. 1916, 3 dez. 1916.

MINAS GERAIS. Ouro Preto, MG, 22 dez. 1892. 27 dez. 1892, 17 dez. 1893, 5 fev. 1894, 11 mar. 1894, 27 mar. 1895, 14 set. 1895, 14 jan. 1896, 20 jun. 1896, 2 jul. 1896, 19 out. 1896, 17 dez. 1896, 18 dez. 1896, 30 mar. 1897, 22 set. 1897.

MINAS GERAIS. Belo Horizonte, MG, $1^{\circ}$ abr. 1898, 7 abr. 1898, 17 abr. 1898, 19 abr. 1898, 11 jul. 1898, 15 jul. 1898, 20 set. 1898, 13 dez. 1898, 30 dez. 1898, 28 fev. 1899, 15 ago. 1899, 6 set. 1899, 18 set. 1899, 20 set. 1899, 21 out. 1899, 4 dez. 1899, 17 fev. 1900, 23 jan. 1920.

O PAIZ. Rio de Janeiro, RJ, 15 ago. 1912, 5 out. 1912, 11 fev. 1913, 17 fev. 1913, 3 ago. 1913, 4 out. 1914, 17 fev. 1915, 2 fev. 1915, 23 fev. 1915, 17 fev. 1916.

O PHAROL. Juiz de Fora, MG, 14 mar. 1909, 14 mar.1903, 16 jun. 1905, $1^{\circ}$ jul 1912, 3 out. 1912, 11 jun. 1915, 1917, 8 set. 1905. 